\title{
The Tunica Stress Conspiracy Revisited
}

\author{
Eric Baković \\ UC San Diego
}

\section{Introduction}

Kisseberth (1970b) argues that a set of facts in Tunica (Haas, 1940) provides evidence for a distinction between relatively obligatory and absolutely obligatory rules. ${ }^{1}$ With respect to an output constraint that unifies a set of rules involved in a 'conspiracy' (on which see also Kisseberth, 1970a), relatively obligatory rules are those that are subject to the constraint and absolutely obligatory rules are those that are not subject to it. The output of an absolutely obligatory rule may thus lead to a violation of the constraint while the output of a relatively obligatory rule may not - that is, the constraint blocks the relatively obligatory rule.

In Kisseberth's (1970b) account of the relevant facts of Tunica, the output constraint at issue is a prohibition on adjacent stresses, referred to here as NO-ClASH (Liberman \& Prince, 1977). Two virtually identical vowel deletion rules, syncope and apocope, behave differently with respect to No-CLASH: apocope is blocked by NO-CLASH, while syncope is not. ${ }^{2}$ That is, apocope is relatively obligatory with respect to NO-CLASH while syncope is absolutely obligatory with respect to NO-CLASH.

The distinction between relatively and absolutely obligatory rules superficially appears to provide further evidence for the explanation of conspiracies in terms of constraint ranking in OT (Prince \& Smolensky 1993/2004): if the output constraint is $\mathbb{C}$, the constraint responsible for the relatively obligatory rule is $\mathbb{R}$, and the constraint responsible for the absolutely obligatory rule is $\mathbb{A}$, then the ranking $\llbracket \mathbb{A} \gg \mathbb{C} \gg \mathbb{R} \rrbracket$ would describe a situation in which $\mathbb{R}$ is 'subject to' (i.e., outranked by) $\mathbb{C}$ while $\mathbb{A}$ is not. $\mathbb{A}$ may thus force violation of $\mathbb{C}$, but $\mathbb{R}$ may not. In Tunica, $\mathbb{C}$ would be No-Clash, $\mathbb{A}$ would be the constraint responsible for the absolutely obligatory syncope rule (call it SYNCOPE for now), and $\mathbb{R}$ would be the constraint responsible for

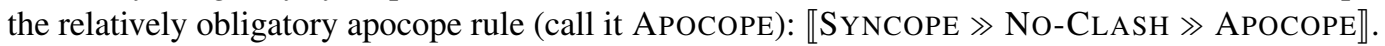

There are two interrelated problems of central concern in this paper. The first problem is the fact that syncope and apocope in Tunica are deeply similar, distinguished by just two details: (i) apocope is subject to NO-CLASH while syncope is not, as already noted, and (ii) syncope applies within words while apocope applies between words. These differences appear to require that syncope and apocope be formulated as distinct processes despite their similarities. The second problem is the fact that NO-CLASH is never violated on the surface in Tunica: the absolutely obligatory syncope rule only produces violations of NO-CLASH in its immediate output. These violations are subsequently repaired by one of two other rules, right destressing and stress shift, that join apocope as part of the conspiracy unified by NO-CLASH. Kisseberth's (1970b) account thus requires both reference to an output constraint (NO-CLASH blocks apocope and triggers right destressing and stress shift) as well as serial ordering (syncope precedes right destressing and stress shift).

An analysis in terms of Stratal OT (Bermúdez-Otero, 1999; Kiparsky, 2000) provides the minimally necessary tools to satisfy both the constraint ranking and the serial derivation demands of the relevant facts of Tunica, and offers an explanation of the basic sameness of syncope and apocope. To preview the result, I argue that the key difference between the lexical and postlexical strata of Tunica is that the constraint responsible for vowel deletion is crucially undominated lexically, leading to the absolute obligatoriness of syncope within words, but crucially dominated postlexically, leading to the relative obligatoriness of apocope between words.

\footnotetext{
* I would like to thank Scott Myers for generously providing me with the hard copy of Kisseberth (1970b) that got me so interested in this topic, and Chuck Kisseberth for letting me in on some of the back story of that manuscript's fate. Thanks also to the anonymous reviewers of the abstract for this paper's ultimate presentation at AMP 2015, and to the folks who asked questions and gave me comments and suggestions there. Remaining errors are mine to keep.

1 Kisseberth (1970a: 305) alludes to this argument; Kisseberth (1972: 223ff) provides a few more details.

2 I am following Haas (1940: 28-30) in referring to the distinction between syncope and apocope; Kisseberth (1970b) refers to syncope as 'internal syncope' and to apocope as 'external syncope'.
}

(C) 2016 Eric Baković

Proceedings of AMP 2015

Completed April 4, 2016 
In $\S 2$ I provide a thorough review of the relevant facts of Tunica, and of Kisseberth's (1970b) analysis thereof: relevant facts about stress are summarized in $\S 2.1$, the syncope, apocope, and other related rules are discussed in $\S 2.2$, and Kisseberth's argument for the relative vs. absolute obligatoriness distinction is reviewed in $\S 2.3$. The proposed Stratal OT analysis is provided in $\S 3$, and $\S 4$ concludes the paper.

\section{The facts}

2.1 Stress. Regular stress in Tunica is stem-initial, as shown by the collection of bisyllabic and trisyllabic stems in (1), the stem + stem compounds in (2), and the prefixed stems in (3). ${ }^{3}$

(1) Stems

\begin{tabular}{|c|c|c|c|c|c|c|c|}
\hline hiru] & 'to rub' & ['hipu] & 'to dance' & ['hara] & 'to sing' & ['jola] & 'to abandon' \\
\hline nara & 'snake' & ['kuwa] & 'bird' & ['wi[i] & 'water' & ['meli] & 'black' \\
\hline lapu] & 'good' & ['kota] & 'gray' & ['?ofta] & 'blu & ['mi & 'red' \\
\hline jaruhki] & 'axe' & ['titihki] & 'bayou' & ['nokufi] & 'bear' & ['Pomahka] & 'alligator' \\
\hline tera $[k i]$ & 'leaf' & ['kapafi] & 'chicken' & ['sosohkana] & 'hawk sp.' & ['romani] & 'heavy' \\
\hline jupahta] & 'cold' & ['sihina] & 'clean' & ['haluhta] & 'beneath' & ['Pay?che] & 'afterwards' \\
\hline
\end{tabular}

(2) Stem + stem compounds ${ }^{4}$

\begin{tabular}{|c|c|c|c|}
\hline $\begin{array}{l}\text { /'nara+'meli/ } \\
\text { /'terafki+'kota/ } \\
\text { /'hahka+'kiri/ } \\
\text { /'nokufi+'nuhtsi/ }\end{array}$ & $\begin{array}{l}\text { 'snake + black' } \\
\text { 'leaf + gray' } \\
\text { 'corn + ground' } \\
\text { 'bear + female' }\end{array}$ & $\begin{array}{l}\longrightarrow \\
\longrightarrow\end{array}$ & 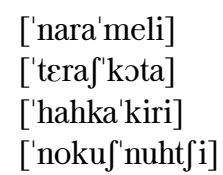 \\
\hline
\end{tabular}

(3) Prefixed stems
/wi+'wana/ ' $2 \mathrm{~ms}+$ want'
/ Pihk+'tira+ht $\mathrm{i} /$ ' $1 \mathrm{~s}+$ cloth + fs'
$/ \mathrm{Pu}+\mathrm{n}+$ 'Jruka/ ' $3 \mathrm{~ms}+\mathrm{dual}+$ be afraid' $\longrightarrow$ [?un'fruka] 'they (masc. dual) are afraid'
$/ \mathrm{Pu}+$ 'nara $+\mathrm{ku} / \quad$ '3ms + snake $+\mathrm{ms}$ ' $\longrightarrow$ [?u'naraku $] \quad$ 'his (masc. sg.) snake'

Some bound stems are pre-stressing, as shown in (4).

(4) Prefixed pre-stressing bound stems

$$
\begin{aligned}
& / \mathrm{iu}+\text { '-ki+ku/ '3ms + maternal uncle }+3 \mathrm{~ms} \text { ' } \rightarrow \quad \text { ['?ukiku }] \text { 'his maternal uncle' } \\
& \text { /hi+'-gatfi+'wali/ '2fs + mother + so-called' } \longrightarrow \text { ['higatfi'wali] 'her stepmother' }
\end{aligned}
$$

Some monosyllabic prefixes and polysyllabic suffixes are inherently stressed (also on the first syllable, in the case of polysyllabic suffixes). ${ }^{5}$ An example of an inherently stressed suffix was already given in (4) above ('wali 'so-called'); further examples of stems with inherently stressed suffixes are given in (5).

(5) Stems with inherently stressed suffixes ${ }^{6}$

$$
\begin{array}{llll}
/ \text { 'jaruhki+'tohku/ } & \text { 'axe + dim.' } & \text { ['jaruh'tohku }] & \text { 'hatchet' } \\
\text { /'wera+n+'Pijan?a+htf/ 'hunt + dual + 1d cond. + sub.' } & \longrightarrow & \text { ['weran'?ijan?ahtf] 'if we (dual) } \\
& & \text { go hunting' }
\end{array}
$$

\footnotetext{
3 Data cited in this paper have been verified via consultation of Haas's grammar (Haas, 1940) and/or dictionary (Haas, 1953), with occasional references to her collection of texts (Haas, 1950). I follow the IPA convention of marking stress with a ' symbol before a stressed syllable (e.g., 'nara'meli); in the dictionary, stress is notated with an acute accent over a stressed vowel (e.g., náraméli 'congo snake'), and in the texts and grammar, it is notated with a ' symbol after a stressed vowel (e.g., na'rame'li) because phrase-final melodies are indicated in these latter two books using accent diacritics (Haas, 1940: 14, fn. 1). Other IPA-leaning deviations from Haas's works include $j$ for $y, \int$ for $\check{s}$, and $t \int$ for $\check{c}$.

4 Note the haplology in the second example in (2), whereby $k V+k \rightarrow k$. Haas (1940: 26, fn. 3) notes that this process is "sporadic", as evidenced by its (optional) nonapplication in the third example. The fourth example also exhibits a vowel deletion that is distinct from the vowel deletion rules of central concern in this paper (Haas, 1940: 23).

5 I do not follow Haas (1940: 36) in distinguishing suffixes from postfixes ("syntactic affixes of the non-inflective type").

6 The first example of (5) undergoes two processes: (i) "[w]hen a stem ending in hki, ši, ni, li, or ri comes to stand before a grammatical element beginning in a consonant, the $i$ may be syncopated unless its stem has a stressed penult" (Haas, 1940: 23) and (ii) "[a] $k$ which would come to stand between an $h$ and a voiceless stop is dropped” (Haas, 1940: 25).
} 
Potential clash between two stressed syllables is generally avoided by destressing the second syllable, as shown by the examples of monosyllabic stems with inherently stressed suffixes in (6) and by the stems with inherently stressed (monosyllabic) prefixes in (7). The rule itself is given in (8). ${ }^{7}$

(6) Right destressing: monosyllabic stem + suffix

\begin{tabular}{|c|c|c|c|c|}
\hline 'ko & & $\longrightarrow$ & & \\
\hline & & & ['so & \\
\hline & & & {$[\mathrm{pc}$} & oks' \\
\hline$P u+' n i+' v$ & ' $3 \mathrm{~ms}+$ tell $+2 \mathrm{~ms}$ smlf.' & & [?u'niwihki] & 'you told him' \\
\hline
\end{tabular}

(7) Right destressing: monosyllabic prefix + stem

\begin{tabular}{|c|c|c|c|c|}
\hline /'ta+'hiru/ & 'ag. + rub' & $\longrightarrow$ & ['tahiru] & 'file' \\
\hline /'ta+'hipu/ & 'ag. + dance' & $\longrightarrow$ & ['tahipu] & 'dancer' \\
\hline /'ta+'hara/ & 'ag. + sing' & $\longrightarrow$ & ['tahara] & 'singer' \\
\hline /'ta+'kuwa/ & 'def. + bird' & & ['takuwa] & 'the bird' \\
\hline /'ta+'nara+ku/ & 'def. + snake + ms' & - & ['tanaraku] & nake (masc. sg.)' \\
\hline 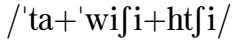 & 'def. + water + fs' & $\longrightarrow$ & ['tawifiht $\left.\int \mathrm{i}\right]$ & 'the water (fem. sg.)' \\
\hline
\end{tabular}

(8) Right destressing: rule

$\left[\begin{array}{c}\mathrm{V} \\ \text { +stress }\end{array}\right] \longrightarrow[$-stress $] /\left[\begin{array}{c}\mathrm{V} \\ + \text { stress }\end{array}\right] \mathrm{C}_{0}$

The alternation between the first example in (6) above and the example in (9) below illustrates that a potential double clash is, as might be expected, resolved by destressing of the medial morpheme.

(9) Right destressing: double clash

/'ta+'ko+'meli/ 'def. + tree + black' $\longrightarrow \quad$ ['tako'meli $] \quad$ 'the hackberry tree'

2.2 Vowel deletion. There are two vowel deletion rules in Kisseberth's (1970b) analysis, syncope (Kisseberth's 'internal syncope') and apocope ('external syncope'). There are also two related processes, one (contraction) discussed in detail by Kisseberth and the other (assimilation) distinguished by Haas (1940).

2.2.1 Syncope. Syncope deletes unstressed, morpheme-final but word-internal vowels when followed by ?-initial morphemes. (The sufficiency of this context will be questioned further below.) As formulated in (10), syncope applies whenever its structural description is met, even if the immediate output contains a stress clash between the syllables flanking the deleted vowel. Syncope is thus absolutely obligatory with respect to No-CLASH, and the resulting stress clash is subsequently repaired by right destressing (8), as shown in (11).

(10) Syncope: rule

$\left[\begin{array}{c}\mathrm{V} \\ - \text { stress }\end{array}\right] \longrightarrow \varnothing /{ }_{-}^{+}$?

(11) Syncope: examples

$\begin{array}{llllll}\text { /'hara+'Paki/ } & \text { 'sing }+3 \text { fs cond.' } & \stackrel{\text { SYNC }}{\longrightarrow} & \text { 'har'Paki } & \stackrel{\text { DESTR }}{\longrightarrow} & \text { ['harPaki] 'she sang' } \\ \text { /'Paka+'Puhki/ } & \text { 'enter }+3 \mathrm{~ms} \text { cond.' } & \stackrel{\text { SYNC }}{\longrightarrow} & \text { 'Pak'Puhki } & \stackrel{\text { DESTR }}{\longrightarrow} & \text { ['PakPuhki] 'he entered' } \\ \text { /'Pami+'Pahkini// 'go + 1s cond.' } & \stackrel{\text { SYNC }}{\longrightarrow} & \text { 'Pam'Pehkini } & \stackrel{\text { DESTR }}{\longrightarrow} & \text { ['PamPehkini] 'I went' }\end{array}$

The examples in (12) below illustrate the necessity of the [-stress] condition on syncope: stressed monosyllabic morphemes followed by ?-initial morphemes do not undergo syncope, only right destressing.

(12) No syncope, only right destressing
$/$ 'ta+'?eru/
'ag. + laugh'
$\longrightarrow \quad$ ['taPeru $]$
'laugher'
/'po+'Puhki/
'look $+3 \mathrm{~ms}$ cond.'
$\longrightarrow \quad$ ['po?uhki]
'he looked'
/'tfu+'?u?uhki+'ani/
'take $+3 \mathrm{~ms}$ repet. + quot.'
$\longrightarrow \quad$ ['tfu?u?uh'keni]
'he always took'

7 All rule formulations in this paper are from Kisseberth (1970b) unless otherwise noted. 
2.2.2 Assimilation and contraction. Note the additional vocalic changes evident in the last example in each of (11) and (12). The first is a case of what Haas (1940: 21-22) calls vocalic assimilation: "when a suffix, postfix, or auxiliary verb beginning in $?$ is added to a stem or word ending in a vowel [...] the vowel following the ? assimilates to the preceding vowel which in turn is syncopated [...]". That example illustrates assimilation of a stressed vowel to an unstressed (and thus subsequently syncopated) vowel; the examples in (13) below illustrate the application of assimilation when the triggering vowel is stressed and thus not syncopated. Because the target vowel in these examples is also stressed, right destressing also applies. ${ }^{8}$

(13) Assimilation between stressed vowels

$$
\begin{array}{lllll}
\text { /'me+'Paki/ 'search + 3fs cond.' } & \stackrel{\text { ASSIM }}{\longrightarrow} & \text { 'me'Peki } & \stackrel{\text { DESTR }}{\longrightarrow} & \text { ['me?kki] 'she searched' } \\
\text { /'po+'?aki/ 'look + 3fs cond.' } & \stackrel{\text { ASSIM }}{\longrightarrow} & \text { 'po'Poki } & \text { DESTR } & \text { ['po?oki] 'she looked' }
\end{array}
$$

The examples in (14) below illustrate assimilation between two unstressed vowels, as well as the progressive persistence of assimilation across $h$ (Haas, 1940: 22).

(14) Assimilation between unstressed vowels (and across $h$ )

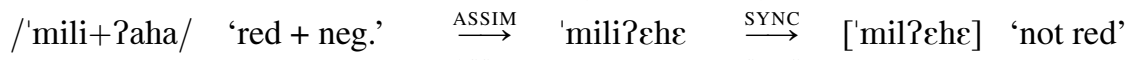

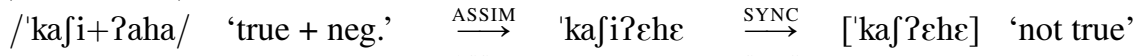

$$
\begin{aligned}
& \text { /'molu+Paha/ 'full + neg.' } \stackrel{\text { ASsIM }}{\longrightarrow} \text { 'molu?ohっ } \stackrel{\text { SYNC }}{\longrightarrow} \text { ['molioho] 'not full' } \\
& \text { /'lapu+?aha/ 'good + neg.' } \stackrel{\text { AsSIM }}{\longrightarrow} \text { 'lapu?ohs } \stackrel{\text { SYNC }}{\longrightarrow} \text { ['lap?oha] 'not good' }
\end{aligned}
$$

The set of assimilations observed are "(1) a after $i$ or $e>\varepsilon$, (2) a after $o$ or $u>\rho$ " (Haas, 1940: 22). This is a proper subset of the set of vocalic contractions observed "when a grammatical element ending in a vowel is combined with a grammatical element beginning in a vowel [...]: (1) $i+e>e$, (2) $u+e>o$, (3) $i$, e, or $\varepsilon+a>\varepsilon$, (4) $u$ or $o+a>o,{ }^{9}$ (5) $a+a>a$ " (Haas, 1940: 21). This is the additional vocalic change illustrated in the last example in (12) above; further examples of contraction are given in (15) below.

(15) Contraction: examples

$$
\begin{array}{lllll}
\text { /Pi+'erusa/ } & \text { '1s + know' } & \longrightarrow & \text { ['Perusa] } & \text { 'I know' } \\
\text { /Pu+'erusa/ } & \text { '3ms + know' } & \longrightarrow & \text { ['Porusa] } & \text { 'he knows' } \\
\text { /'mili+'ani/ } & \text { 'red + quot.' } & \longrightarrow & \text { [mi'leni] } & \text { 'it is red, they say' } \\
\text { /'tafle+'ani/ } & \text { 'beautiful + quot.' } & \longrightarrow & \text { [taf'leni] } & \text { 'it is beautiful, they say' } \\
\text { /'molu+'ani/ } & \text { 'full + quot.' } & \longrightarrow & \text { [mo'loni] } & \text { 'it is full, they say' } \\
\text { /'ni+ku+'ani/ } & \text { 'say + 3ms + quot.' } & \longrightarrow & \text { [ni'koni] } & \text { 'he says, they say' } \\
\text { /'nara+'ani/ } & \text { 'snake + quot.' } & \longrightarrow & \text { [na'rani] } & \text { 'it is a snake, they say' }
\end{array}
$$

If the contracted vowel is followed by $h$, as illustrated in (16) below, then the following vowel is also assimilated (Haas, 1940: 21). This is parallel to the progressive persistence of assimilation across $h$ in (14), but this time triggered by a stressed vowel produced by contraction.

(16) Contraction and assimilation across $h$

$$
\begin{aligned}
& / \mathrm{ti}+\text { 'ahaja }+\mathrm{ku} / \quad \text { '3fs }+ \text { sibling (opp. sex) }+\mathrm{ms} \text { ' } \longrightarrow \text { ['tehsjaku }] \text { 'her brother' } \\
& \text { /?u+'ahaja+ht } \mathrm{i} / \quad \text { '3ms + sibling (opp. sex) +fs' } \rightarrow \text { ['Pohojaht fi] 'his sister' } \\
& / \mathrm{iu}+\text { 'ehekuma }+\mathrm{ku} / \text { ' } 3 \mathrm{~ms}+\text { younger brother }+\mathrm{ms} \text { ' } \longrightarrow \text { ['?ohokumaku }] \text { 'his younger brother' }
\end{aligned}
$$

2.2.3 Stress shift. Note that in the first two examples in (15) above, stress remains on the stem-initial vowel, now contracted with the (unstressed) vowel of the prefix. The remaining examples in (15) involve the inherently stressed quotative suffix 'ani attached to vowel-final stems, which are themselves stressed on the preceding vowel. Contraction of the stem-final vowel with the suffix-initial vowel thus leads to potential stress clash. We might then expect right destressing to repair this in favor of the stem stress, but instead we see retention of the suffix stress on the contracted vowel: mi'leni 'it is red, they say', not *'mileni.

Moreover, note that when an unstressed prefix is added to these forms, the initial stress of the stem which is simply lost in the unprefixed examples in (15) - appears to shift to the prefix, as shown in (17).

\footnotetext{
8 The serial order between assimilation and right destressing is not crucial in (13), but is inferred from the fact that syncope must apply after assimilation, as shown in (14), and before right destressing, as was shown in (11).

9 "Instances of $o+a$ do not happen to occur." (Haas, 1940: 21, fn. 1)
} 
(17) Stress shift: examples

$$
\begin{aligned}
& \text { /te+'mili+'ani/ 'all-about + red + quot.' } \longrightarrow \quad \text { ['temi'leni] 'it is red all about, they say' } \\
& / \mathrm{lu}+\text { 'ni+ku+'ani/ '3ms + say }+3 \mathrm{~ms}+\text { quot.' } \longrightarrow \quad \text { ['Puni'koni] 'he says to him, they say' }
\end{aligned}
$$

Both Haas (1940: 28) and Kisseberth (1970b: 10-11) take the examples in (17) as evidence for a rule of stress shift. Kisseberth's formulation in (18) uses angled brackets to account for both the examples in (17) where there's a prefix vowel to shift the stem stress onto and the examples in (15) where there is no prefix. ${ }^{10}$

(18) Stress shift: rule

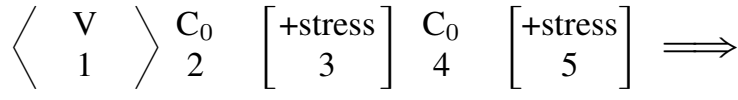

$$
\begin{aligned}
& \left\langle\begin{array}{c}
1 \\
+ \text { stress }
\end{array}\right\rangle^{2} \quad\left[\begin{array}{c}
3 \\
- \text { stress }
\end{array}\right] \quad 4 \quad 5
\end{aligned}
$$

Because right destressing and stress shift apply to the same inputs and result in distinct outputs, the full analysis relies crucially on serial ordering: first assimilation, then syncope, then right destressing, then contraction, then stress shift. Derivations of key forms are given in (19) below.

Derivations

$\begin{array}{rcccc}\text { UR } & \text { a. /'hara+'Paki/ } & \text { b. /'lapu+'Paha/ } & \text { c. /'mili+'ani/ } & \text { d. /te+'mili+'ani/ } \\ \text { Assimilation } & - & \text { 'lapu'Poha } & - & - \\ \text { Syncope } & \text { 'har'?aki } & \text { 'lap'?oha } & - & - \\ \text { Right destressing } & \text { 'har?aki } & \text { 'lap?oha } & - & \text { 'mi'leni } \\ \text { Contraction } & - & - & \text { te'mi'leni } \\ \text { Stress shift } & - & - & \text { mi'leni } & \text { 'temi'leni } \\ \text { SR } & \text { ['har?aki] } & \text { ['lap?oha] } & \text { [mi'leni] } & \text { ['temi'leni] } \\ & \text { 'she sang' } & \text { 'not good' } & \text { 'it is red, they say' } & \text { 'it is red all about, they say' }\end{array}$

The derivation in (19a) illustrates a stem with an inherently stressed, ?-initial suffix; syncope applies first, resulting in stress clash, which is subsequently repaired by right destressing. The derivation in (19b) is similar except that the first vowel of the suffix undergoes assimilation before the stem-final vowel is deleted by syncope. The derivations in $(19 \mathrm{c}, \mathrm{d})$ both illustrate a stem with an inherently stressed, vowel-initial suffix. Syncope doesn't apply because there is no ?; right destressing doesn't apply either, because there is no stress clash (yet). So contraction first is the first rule to apply, resulting in stress clash, which is in this case subsequently repaired by stress shift. In (19c), stress shift just destresses the stem vowel, there being no preceding vowel to shift the stress to; in (19d), stress shifts to the preceding prefix vowel.

This analysis of course requires that syncope and contraction be distinct rules, with right destressing crucially applying between them, and also that assimilation and contraction be distinct rules, with both syncope and right destressing crucially applying between them. There is good reason to think, however, that these three rules are more deeply related than this. Consider the unusual context of syncope: an unstressed vowel deletes before ?. Especially given that in all forms matching this structural description there will be another vowel following the ?, it seems reasonable to assume that the motivation for syncope is instead the avoidance of hiatus and that the intervening $?$ is ignored (Borroff, 2003, 2007). This assumption makes better sense of the relation between assimilation and contraction. As already noted, the set of observed assimilations is a proper subset of the set of observed contractions; the key difference is that contraction occurs between immediately adjacent vowels while assimilation (and, subsequently, syncope) occurs across glottal stop. If we

\footnotetext{
${ }^{10}$ Leftward stress shift is also evident "[w]hen a monosyllabic noun stem is preceded by a stressless monosyllabic prefix [and] followed by a monosyllabic suffix, a polysyllabic suffix, or another stem" (Haas, 1940: 28): $t i+$ ' $r i+\int i$ ' $3 \mathrm{fs}$ + house + to' $\rightarrow$ 'tirifi 'to her house', ? $u+$ 'sa $\mathrm{k} u$ '3ms + dog + ku' $\rightarrow$ '?usaku 'his dog', ?u+'sa+'sinima '3ms + $\operatorname{dog}+\mathrm{fp}$ ' $\rightarrow$ 'Pusa'sinima 'his dogs', ?u+'ja+'tahkifi '3ms + deer + skin' $\rightarrow$ 'Puja'tahkifi. Generalizing stress shift to accommodate these examples is complicated by the fact that "[m]onosyllabic verb stems, in contrast to noun stems, retain their primosyllabic stress under such circumstances": $? u+$ 'po+wi ' $3 \mathrm{~ms}+$ see $+3 \mathrm{~ms}$ ' $\rightarrow$ ?u'powi 'he saw him'.
} 
assume instead that assimilation also applies between adjacent vowels, ignoring glottal stop, then contraction can be simply understood as the compound result of assimilation and syncope. ${ }^{11}$

The problem with this analysis, of course, is the fact that forms that undergo syncope (with or without assimilation) are subject to right destressing, while those that undergo contraction are subject to stress shift. I do not have a solution to this problem to propose at present, but the future pursuit of one seems worthwhile.

2.2.4 Apocope. Apocope deletes unstressed, word-final vowels when followed by P-initial words, as shown by the examples in (20); the rule is given in (21). Apocope applies whenever its structural description is met except when its output would result in a stress clash between the syllables flanking the deleted vowel, as shown by the examples in (22). Apocope is thus relatively obligatory with respect to No-CLASH. ${ }^{12}$

(20) Apocope: examples

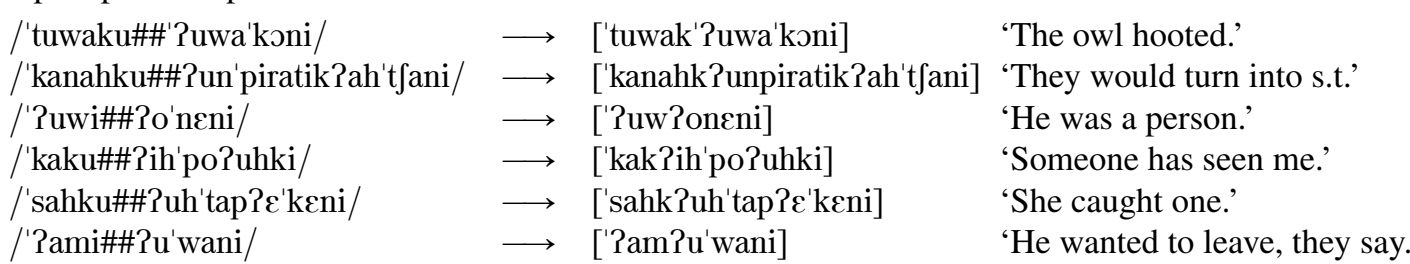

(21) Apocope: rule

$\left[\begin{array}{c}\mathrm{V} \\ - \text { stress }\end{array}\right] \longrightarrow \varnothing / \ldots \#$ ?

(22) Blocking of apocope

/'juru\#\#'Pamar?ehe/ $\longrightarrow \quad$ ['juru'Pamar?ehe] 'not long enough'

\begin{tabular}{|c|c|c|c|}
\hline & $(\stackrel{\mathrm{APOC}}{\longrightarrow}$ & 'jur'Pamar?che & *['jurPamar?che]) \\
\hline \multirow[t]{2}{*}{ /'sahku\#\#'?uhkifkan/ } & $\longrightarrow$ & ['sahku'?uhkifkan] & 'although there is one' \\
\hline & $(\stackrel{\mathrm{APOC}}{\longrightarrow}$ & 'sahk'?uhkifkan & $\stackrel{\text { DESTR }}{\longrightarrow} *$ ['sahkPuhkifkan]) \\
\hline \multirow[t]{2}{*}{ /Pu'Jira\#\#'Pahkihtan/ } & $\longrightarrow$ & [?u'Jira'Pahkihtan] & 'behind his back' \\
\hline & & Pu'Jir'Pahkihtan & *[?u'(irPahkihtan \\
\hline
\end{tabular}

2.3 The relative and the absolute. One of the central points of Kisseberth (1970b) is that the theory of generative phonology at the time had no means of capturing the fact that right destressing (8), stress shift (18), and apocope (21) share in common that the avoidance of stress clash. In the absence of a theory for how rules can be made to be subject to constraints, the fact that apocope applies except when it would create a stress clash means that the rule must arguably be complicated in the manner shown in (23). ${ }^{13}$

(23) Complicated apocope

$\left[\begin{array}{c}\mathrm{V} \\ \text {-stress }\end{array}\right] \longrightarrow \varnothing /\left[\begin{array}{c}\mathrm{V} \\ \alpha \text { stress }\end{array}\right] \mathrm{C}_{0} \ldots \# ?\left[\begin{array}{c}\mathrm{V} \\ \beta \text { stress }\end{array}\right]$

The complicated formulation of apocope in (23) misses two key generalizations. First, as was just noted, it misses the fact that right destressing, stress shift, and apocope all share the function of stress clash avoidance: No-CLASH triggers right destressing and stress shift, and it blocks apocope. Second, it also misses the fact that syncope and apocope are clearly related rules: both delete a unit-final unstressed

\footnotetext{
${ }^{11}$ In discussing contraction, Kisseberth (1970b: 9-10) parenthetically suggests an analysis similar to the one proposed in the text: "Consideration of additional data suggests that, in fact, two steps are involved — first, assimilation of the second vowel in the sequence to the first, then deletion of the first vowel." Assimilation is not otherwise discussed in Kisseberth's paper, however, and there is no suggestion that "deletion of the first vowel" might be reducible to syncope.

${ }^{12}$ Word-internal structure and derivation is not indicated in any of these examples illustrating phrase-level phonology. Haas (1940: 29) also notes that apocope is blocked "[w]hen the final vowel of the [first] word is itself preceded by ?",

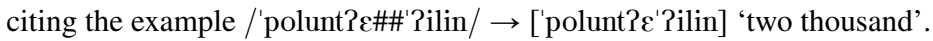

13 This is Kisseberth's (1970b: 15) formulation, where $\alpha \neq \beta$, and thus according to which apocope also does not apply if it would create a stress lapse. To my knowledge, there are no data to confirm or disconfirm this prediction.
} 
vowel when followed by a unit-initial glottal stop (or, in the alternative view sketched at the end of $\S 2.2 .3$ above, both delete the first of two vowels in hiatus). In Kisseberth's (1970b: 16) own words: "The limitation on [apocope] is a perfectly natural one in the grammar of Tunica; the surprising thing is not that [apocope] is constrained in the fashion that it is, but rather that the constraints on [apocope and syncope] are different." Kisseberth (1970b: 22) proposes to collapse the apocope (21) and syncope (10) rules as shown in (24).

(24) Vowel deletion

$$
\left[\begin{array}{c}
\mathrm{V} \\
- \text { stress }
\end{array}\right] \longrightarrow \varnothing /-\left\{\begin{array}{c}
+ \\
\# \#
\end{array}\right\} \text { ? }
$$

Under the assumption that every rule is subject to every (relevant) constraint unless marked to the contrary, Kisseberth (1970b: 22) proposes that "the first subcase of [(24)] is marked as not being subject to the adjacent stressed syllables constraint [...] whereas the other is not so marked." This is the essence of the relative vs. absolute obligatoriness distinction: the "first subcase" of (24) is syncope, which is absolutely obligatory because it "is marked as not being subject to" NO-CLASH; the second subcase is apocope, which is relatively obligatory because it "is not so marked" and so is subject to NO-CLASH.

OT provides the basic tools for formalizing what it means to be "marked as not being subject to" a constraint like NO-CLASH and to be "not so marked" - differential ranking of relevant constraints with respect to No-CLASH. An analysis along these simplified lines fails in two respects, however.

First, there is the explanatory cost. If the ranking is $\llbracket$ SYNCOPE $\gg$ NO-CLASH $\gg$ APOCOPE $\rrbracket$ that is, the constraint responsible for syncope and the constraint responsible for apocope are ranked differently with respect to No-CLASH - then the essential sameness of syncope and apocope reflected (albeit imperfectly) in (24) is completely lost. Second, there is the observational cost. As Haas (1940: 13) makes clear, "[a] phrase or a word may have one or more stressed syllables but these are never consecutive" (emphasis added). ${ }^{14}$ With right destressing and stress shift to clean up the mess, NO-CLASH is not violated by any Tunica surface forms. NO-CLASH must thus not be dominated by any constraint in Tunica.

To sum up, there are three key analytical desiderata to be captured by an analysis of the facts discussed in this paper. First, there is the fact that syncope and apocope are essentially the same process, the former applying within words and the latter applying between words; this requires that one and the same rule or constraint be responsible for both. Second, there is the fact that NO-CLASH must block the application of apocope but allow the application of syncope; this requires that the two be differentiated somehow, even if they are essentially the same process. Third, there is the fact that NO-CLASH is unviolated on the surface in Tunica, and that violations of NO-CLASH introduced by syncope (and by contraction, insofar as it is distinct from syncope) are ultimately repaired by right destressing (and stress shift, in the case of contraction).

\section{Stratal OT analysis}

Stratal OT (Bermúdez-Otero, 1999; Kiparsky, 2000) provides the minimally necessary tools to capture the three key analytical desiderata noted above. Given one of the essential differences between syncope and apocope - that syncope applies within words while apocope applies between words - it is safe to assume that syncope is a lexical process resulting from some ranking of constraints in the word-level stratum and that apocope is a postlexical process resulting from some ranking of constraints in the phrase-level stratum. Importantly, both processes involve the same constraints; only their ranking differs between strata, which results in the other essential difference between syncope and apocope: that syncope is absolutely obligatory while apocope is relatively obligatory with respect to NO-CLASH.

Building on the discussion at the end of $\$ 2.2 .3$, I assume for present purposes that the constraint responsible for vowel deletion is No-HIATUS, violated equally by VV and V?V sequences (Borroff, 2003, 2007), which of course must crucially dominate MAX-V, the faithfulness constraint against vowel deletion (McCarthy \& Prince, 1999). A key constraint that might otherwise prevent right destressing and stress shift is the faithfulness constraint FAITH(stress). A more complete analysis of stress placement in Tunica would have to spell out many more details than this, to be sure, but for our purposes it is sufficient to stipulate that stems and inherently stressed affixes have stress specified (on their first vowels) underlyingly and that FAITH(stress) is violated by each of the two unfaithful input-output mappings identified in (25).

\footnotetext{
${ }^{14}$ Or, as Kisseberth (1970b: 5) paraphrases it: "although multiple occurrences of stress are possible in the word [...] Tunica does not tolerate phonetically adjacent stressed vowels either within the word or within the phonological phrase."
} 


\section{(25) Violations of FAITH(stress)}

a. Underlying stressed vowel $\longrightarrow$ word-level unstressed vowel

b. Word-level stressed vowel $\longrightarrow$ phrase-level unstressed vowel

It is reasonable to assume that violation of FAITH(stress) is somehow mitigated when stress shift is able to actually shift stress onto a preceding vowel, as it does in (17), as opposed to only destressing a vowel as it does in (15) and as right destressing does in (6) and (7). Working out such details is also a matter for a more complete analysis of stress placement in Tunica, something I will have to leave for future work.

To account for blocking of apocope in the phrase-level stratum, NO-CLASH and FAITH(stress) must be ranked above No-HIATUS (which must itself be ranked above MAX-V, of course), as shown in (26). The optimal candidate in (26a) fails to undergo apocope, violating the bottom-ranked NO-HIATUS constraint. This is a necessary sacrifice due to the higher rank of NO-CLASH, violated by the candidate with apocope in (26b), and of FAITH(stress), violated by the candidate with both apocope and destressing in (26c).

(26) Postlexical blocking of apocope

\begin{tabular}{|c|c|c|c|c|c|}
\hline \multirow[t]{4}{*}{ Phrase-level } & 'juru\#\#'?amar?ehe & No-Clash & FAITH(stress) & No-Hiatus & MAX-V \\
\hline & a. ['juru'?amar?she] & & & $*$ & \\
\hline & b. ['jur'PamarPehe] & $* !$ & & & $*$ \\
\hline & 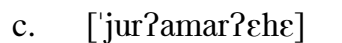 & & $* !$ & & $*$ \\
\hline
\end{tabular}

For the word-level stratum, there are two paths that can be pursued. The first path accomplishes both syncope and destressing at the word-level with a lexical ranking in which both NO-HIATUS and NO-CLASH dominate FAITH(stress); No-HiATUS also dominates MAX-V, of course. The result for a relevant example is given in (27). The faithful candidate in (27a) has no syncope and so fatally violates NO-HIATUS. The candidate in (27b) has syncope but no destressing, fatally violating NO-CLASH. The optimal candidate in (27c) has both syncope and destressing, violating lower-ranked FAITH(stress) and MAX-V. (When the output of this word-level mapping is input to the phrase-level ranking in (26), a faithful result is optimal.)

(27)

Lexical syncope and destressing Word-level

\begin{tabular}{|c|c|c|c|c|}
\hline /'hara+'Paki/ & No-Hiatus & No-Clash & FAITH(stress) & MAX-V \\
\hline 'hara'?aki & $* !$ & & & I \\
\hline b. 'har'?aki & & $* !$ & & $*$ \\
\hline c. 'harPaki & & & $*$ & $*$ \\
\hline
\end{tabular}

The second path hews more closely to Kisseberth's (1970b) analysis: syncope creates violations of NoCLASH lexically, and these violations are repaired by destressing postlexically. This requires a lexical ranking in which both FAITH(stress) and No-HIatus dominate No-Clash (and in which No-Hiatus dominates MAX-V, of course), as shown in (28). The optimal word-level candidate in (28b) undergoes syncope but not destressing, violating NO-CLASH and MAX-V, and thus avoids the NO-HIATUS violation of the faithful candidate in (28a) and the FAITH(stress) violation of the syncope-and-destressing candidate in (28c).

(28) Lexical syncope

Word-level

\begin{tabular}{|c|c|c|c|c|}
\hline /'hara+'Paki/ & FAITH(stress) & No-Hiatus & No-Clash & MAX-V \\
\hline a. 'hara'?aki & & $* !$ & & 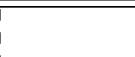 \\
\hline b. 'har'?aki & & & $*$ & $*$ \\
\hline c. 'har?aki & $* !$ & & & $*$ \\
\hline
\end{tabular}


This word-level output is then the input to the phrase level, the ranking of which must simply be further articulated than the one in (26) by having NO-CLASH also dominate FAITH(stress), as shown in (29). The faithful candidate in (29a) still violates No-CLASH, this time fatally, forcing destressing in the optimal candidate in (29b) via violation of FAITH(stress).

(29) Postlexical destressing

\begin{tabular}{|c|c|c|c|c|c|}
\hline \multirow[t]{3}{*}{ Phrase-level } & 'har'?aki & No-Clash & FAITH(stress) & No-Hiatus & MAX-V \\
\hline & a. ['har'?aki] & $* !$ & & & \\
\hline & b. ['har?aki] & & $*$ & & \\
\hline
\end{tabular}

Along the first path, the focal point of the difference between the lexical and postlexical rankings is NoHIATUS, which moves from undominated status lexically (27) to dominated status postlexically (26). This difference between the lexical and postlexical rankings holds of the second path as well, but the focal point along the second path is NO-CLASH, which moves from dominated status lexically (28) to undominated status postlexically (29). The second path thus conforms with Kiparsky's $(2013 ; 2015)$ recent hypothesis that two strata may only be critically distinguished by the promotion of constraints to undominated status in the later stratum. Whether this is a good reason to choose the second path over the first will depend on the support that this hypothesis may or may not receive in future work in Stratal OT.

\section{Conclusion}

In this paper I have proposed to unify the syncope and apocope rules of Tunica by attributing them to the activity of the same constraint, No-HiATUS, ranked differently in the lexical and postlexical levels of a Stratal OT grammar. Lexically, No-HiATUS is undominated and is thus responsible for the absolute obligatoriness (= inviolability) of syncope. Postlexically, No-HIATUS is crucially dominated by NO-CLASH, and this ranking is responsible for the relative obligatoriness (= violability) of apocope.

One critical difference between this unified analysis of syncope and apocope and the one proposed by Kisseberth (1970b) - recall the collapsed vowel deletion rule in (24) — is that the present analysis explains why it is that apocope is the one of the two that is blocked. Under Kisseberth's (1970b) analysis, either one of the subcases of the collapsed vowel deletion rule can be "marked as not being subject to" No-CLASH, such that syncope could just as easily be the one of the two that is blocked. This is not possible under the present analysis: if No-Hiatus is promoted to undominated status postlexically so that vowel deletion between words can apply without restrictions, then vowel deletion within words will also apply without restrictions, albeit now postlexically). In other words, the present analysis allows only syncope or both syncope and apocope to be subject No-CLASH, while Kisseberth's (1970b) analysis also allows only apocope to be subject to No-ClaSH. The present analysis is therefore in this respect more restrictive than Kisseberth's.

The proposed analysis also unifies the conspiracy of apocope, right destressing, and stress shift under the banner of NO-CLASH. By Kisseberth's own admission, his analysis falls short of this goal in that he does not propose a mechanism by which right destressing and stress shift are triggered by NO-CLASH. ${ }^{15}$ To mitigate this shortcoming of the analysis, Kisseberth (1970b: 25) suggests that "a derivational constraint does not add to the complexity of a grammar as a whole if the sequence which it prevents rules from creating is identical to the sequence to which some phonological rule in the language applies." In other words, No-CLASH is a relatively cost-free output constraint in a grammar like Tunica's because there exists a rule (in fact, two) the structural description of which is identical to No-CLASH. ${ }^{16}$ But note what this suggestion implies: it should also be relatively cost-free to have NO-HIATUS as an output constraint in the grammar of Tunica, given the existence of both syncope and apocope (not to mention contraction), and yet No-HiATUS must be violated in some examples that meet the structural description of apocope. So, some prioritization of these output constraints is necessary, which is of course precisely the machinery that OT provides.

${ }^{15}$ Kisseberth (1970a: 304ff) admits to falling short of this goal for the theory of conspiracies, too.

${ }^{16}$ Kisseberth may mean to suggest that the existence of both right destressing and stress shift means that NO-CLASH is even less costly than it would otherwise be, but there's no indication about how these cost differences might be calculated. 


\section{Postscript}

I became aware of Hammond's (1984) fourth dissertation chapter ("Rhythm and Destressing in Tunica") only after writing up the entirety of the preceding. Hammond's (1984: 172ff) discussion of the relationship among syncope, apocope, and stress clash avoidance focusses on how his theory of destressing could be used to determine which of the two vowel deletion rules is blocked, which is of course also a central concern of the present paper; I would say that the most significant difference between our approaches is the emphasis placed on the stratal organization of grammar here. There are several ways in which Hammond's discussion and analysis is more thorough than what is presented here, and I encourage interested readers of this paper to also consult Hammond (1984) — as well as Haas (1940, 1950, 1953) and Kisseberth (1970b), of course.

\section{References}

Bermúdez-Otero, Ricardo (1999). Constraint interaction in language change: quantity in English and Germanic [Opacity and globality in phonological change]. Doctoral dissertation, University of Manchester \& Universidad de Santiago de Compostela.

Borroff, Marianne L. (2003). Against an ONSET Approach to Hiatus Resolution. ROA-586, Rutgers Optimality Archive, http://roa.rutgers.edu.

Borroff, Marianne L. (2007). A Landmark Underspecification Account of the Patterning of Glottal Stop. Doctoral dissertation, SUNY Stony Brook. ROA-904, Rutgers Optimality Archive, http://roa.rutgers.edu.

Haas, Mary R. (1940). Tunica. J. J. Augustin, Extract from the Handbook of American Indian Languages, vol. 4. New York.

Haas, Mary R. (1950). Tunica Texts, vol. 6 of University of California Publications in Linguistics. University of California Press, Berkeley and Los Angeles.

Haas, Mary R. (1953). Tunica Dictionary, vol. 6 of University of California Publications in Linguistics. University of California Press, Berkeley and Los Angeles.

Hammond, Michael (1984). Constraining Metrical Theory: A Modular Theory of Rhythm and Destressing. Ph.D. thesis, UCLA.

Kiparsky, Paul (2000). Opacity and cyclicity. The Linguistic Review 17, 351-367.

Kiparsky, Paul (2013). The residue of opacity. Talk presented at the Workshop on Opacity in Grammar, University of Leipzig.

Kiparsky, Paul (2015). Stratal OT: A Synopsis and FAQs. Hsiao, Yuchau E. \& Lian-Hee Wee (eds.), Capturing Phonological Shades Within and Across Languages, Cambridge Scholars Library, Newcastle upon Tyne, 2-44.

Kisseberth, Charles W. (1970a). On the functional unity of phonological rules. Linguistic Inquiry 1, 291-306.

Kisseberth, Charles W. (1970b). The Tunica stress conspiracy. Unpublished manuscript, University of Illinois, Urbana.

Kisseberth, Charles W. (1972). On derivative properties of phonological rules. Brame, Michael (ed.), Contributions to Generative Phonology, University of Texas Press, 201-228.

Liberman, Mark \& Alan Prince (1977). On stress and linguistic rhythm. Linguistic Inquiry 8, 249-336.

McCarthy, John J. \& Alan Prince (1999). Faithfulness and identity in prosodic morphology. Kager, René, Harry van der Hulst \& Wim Zonneveld (eds.), The Prosody-Morphology Interface, Cambridge University Press, Cambridge, 218309. ROA-216, Rutgers Optimality Archive, http://roa.rutgers.edu.

Prince, Alan \& Paul Smolensky (1993). Optimality Theory: Constraint Interaction in Generative Grammar. Technical Report RuCCS-TR-2, Rutgers University Center for Cognitive Science. ROA-537, Rutgers Optimality Archive, http://roa.rutgers.edu. 